\section{Consecutive Annual Decreases in TB Incidence}

New York City and California recently announced consecutive annual decreases in reported TB incidence. New York City announced a 7.4\% decrease in reported cases for 1994. Combined with the decline in 1993 cases, this brought New York City's TB incidence to $21.4 \%$ below the level reported in 1992. These trends are viewed as a clear response to aggressive TB prevention efforts which, through expanded use of directly observed therapy, raised the rate for completion of therapy from 50\% in 1989 to approximately $90 \%$ currently.

California experienced a $6 \%$ decrease in reported TB for 1994. Combined with a $4 \%$ decrease from the year before, this reduced California's incidence 10\% below the 1992 level. Public health officials were careful to note that, despite the encouraging trend in incidence, 1994 TB cases in California were still 39\% above the level reported in 1985 .

A 1994 survey of TB in the Department of Veterans Affairs (VA) also showed a decrease in TB. The survey showed a 4.4\% decrease from 1993 in the incidence of TB in the $170 \mathrm{VA}$ facilities, which is consistent with the national trend.

These reductions appear to be widespread; indeed, according to the May 26, 1995, MMWR, a total of 27 states reported fewer TB cases than in 1993; 31 states reported fewer cases in 1993 than in 1992; and 16 states reported fewer cases in both 1993 and 1994 than in the respectively preceding year.

\section{Joint Commission N ow Accredits Ambulatory Care Infusion Centers}

The Joint Commission on Accreditation of Healthcare Organizations has started a new accreditation process for ambulatory care infusions centers. To qualify as an ambulatory care infusion center, an organization must dispense and administer medications by infusion to ambulatory patients, in an area especially designed for this purpose, under the supervision of a licensed healthcare professional.

There are predominantly two types of centers, each of which will undergo a different survey process: physicianbased centers (usually licensed as part of a physicians office or practice) and freestanding centers (most commonly owned and operated by home care organizations). Because of the unusual nature of these infusion centers, the majority of services, particularly the complex pharmacy services, were not addressed specifically by any standards or survey process.

Hospital-based ambulatory care infusion centers will not be surveyed under this new process, but rather as a patient care unit following the standards in the Accreditation Manual for Hospitals. For further information, contact Network and Ambulatory Health Care Accreditation Services at (708) 9165731.

FROM: Joint Commission now accredits ambulatory care infusion centers. Joint Commission Perspectives. March/ April 1995;15(2):15-16.

\section{Appeals Court Upholds H ospital Firing of HIV-Positive Physician}

A federal appeals court said that a Baltimore, Maryland, hospital acted properly in firing an HIV-infected neurosurgical resident because of the "significant risk" of transmission to patients during surgery. The Fourth US Circuit Court of Appeals said that it would not substitute its judgment for that of the hospital in assessing the risk to patients, even though it acknowledged that there have been no documented cases of surgeon-to-patient transmission of HIV

This decision represents the first time a federal appeals court ruled on whether an HIV-positive surgeon is protected from dismissal under the Americans with Disabilities Act (ADA). Although this ruling is binding only in the Fourth Circuit (covering Maryland, North Carolina, South Carolina, Virginia, and West Virginia), it can be cited as a precedent in other jurisdictions.

The neurosurgical resident, John Doe, was in the third year of training at the University of Maryland Medical System Corp. in Baltimore when he stuck himself with a needle while treating a patient who may have been HIV positive. Upon learning that Doe was HIV positive, the hospital suspended him from surgery, pending a recommendation from a panel of experts. The panel recommended that Doe be allowed to continue surgery, with the exception of a few procedures.

The hospital administrators overruled the panel of experts, ended Doe's surgical practice, and offered him an alternative residency in a nonsurgical field. Doe sued and charged that his firing violated Title II of the ADA and Section 504 of the Rehabilitation Act, which bars discrimination in hospitals that receive federal funds. Both statutes prohibit discrimination against a "qualified individual with a disability," unless the person poses a significant health or safety risk that cannot be reduced through a reasonable accommodation, such as modifying work practices. The federal district court concluded that Doe was not entitled to relief under the ADA or the Rehabilitation Act. The key question for the appeals court was, "Who should decide whether Doe posed a 'significant risk' to patients?" Both sides used the CDC's guidelines on exposure-prone invasive procedures to defend their position. The hospital attorneys cited the section of the guidelines that recommends that each hospital identify exposure-prone procedures and determine whether, and under what circumstances, an HIV-infected healthcare worker should be allowed to perform those procedures. In addition, attorneys representing the hospital cited a 1992 CDC study published by J. Tokars in the June 3, 1992, issue of JAMA that found surgeons accidentally injured themselves in $6.9 \%$ of all surgeries.

The court said that even if Doe takes extra precautions, some measure of risk always will exist. In addition, the court said that the hospital had "thoroughly deliberated" before concluding that neurosurgical procedures were exposure prone, and the court was reluctant to substitute their judgment for that of the hospital. 